Virginia Commonwealth University VCU Scholars Compass

2001

\title{
Reactivity and electronic structure of aluminum clusters: The aluminum-nitrogen system
}

\author{
B. D. Leskiw
}

The Pennsylvania State University

A. W. Castleman Jr.

The Pennsylvania State University

C. Ashman

Virginia Commonwealth University

S. N. Khanna

Virginia Commonwealth University

Follow this and additional works at: http://scholarscompass.vcu.edu/phys_pubs

Part of the Physics Commons

Leskiw, B. D., Castleman, A. W., Ashman, C., et al. Reactivity and electronic structure of aluminum clusters: The aluminum-nitrogen system. The Journal of Chemical Physics 114, 1165 (2001). Copyright (C) 2001 AIP Publishing LLC.

\section{Downloaded from}

http://scholarscompass.vcu.edu/phys_pubs/153

This Article is brought to you for free and open access by the Dept. of Physics at VCU Scholars Compass. It has been accepted for inclusion in Physics Publications by an authorized administrator of VCU Scholars Compass. For more information, please contact libcompass@vcu.edu. 


\title{
Reactivity and electronic structure of aluminum clusters: The aluminum-nitrogen system
}

\author{
B. D. Leskiw and A. W. Castleman, Jr. \\ Departments of Chemistry and Physics, Eberly College of Science, 152 Davey Laboratory, \\ The Pennsylvania State University, University Park, Pennsylvania 16802 \\ C. Ashman and S. N. Khanna \\ Department of Physics, Virginia Commonwealth University, Richmond, Virginia 23112-2000
}

(Received 18 July 2000; accepted 24 October 2000)

\begin{abstract}
The stability of anionic aluminum-nitrogen clusters has been examined and $\mathrm{Al}_{2} \mathrm{~N}^{-}, \mathrm{Al}_{3} \mathrm{~N}_{2}^{-}$, $\mathrm{Al}_{5} \mathrm{~N}_{2}^{-}, \mathrm{Al}_{6} \mathrm{~N}_{3}^{-}, \mathrm{Al}_{8} \mathrm{~N}_{3}^{-}$, and $\mathrm{Al}_{9} \mathrm{~N}_{2}^{-}$are found to be particularly stable. Theoretical density functional calculations on neutral and anionic $\mathrm{Al}_{n} \mathrm{~N}(n=1-8)$ clusters were performed and the stability and reaction energetics with oxygen examined. Clusters requiring less than $5.7 \mathrm{eV}$ to remove an electron and an $\mathrm{Al}$ atom are shown to be resistant to the reaction with oxygen. (C) 2001 American Institute of Physics. [DOI: 10.1063/1.1333017]
\end{abstract}

\section{INTRODUCTION}

A vast number of investigations have attempted to specifically address the stability of various metal-containing clusters. ${ }^{1-6}$ These studies have implemented both experimental and theoretical approaches, with efforts focused mainly on understanding the factors that influence the reactivities and properties of cluster systems. Recently, another unified objective has surfaced. Instead of emphasizing the search for highly stable species, attention is shifting toward the prospects of forming new materials, through the concept of cluster assembly. ${ }^{3-5}$ Ideally, these species would preserve their stable constituent properties and ultimately retain their integrity when coupled to one another and/or the appropriate counter-ion, thereby making them suitable as building blocks in the process of synthesizing new nanoscale materials.

With these goals in mind, the search to develop tailordesigned materials, through the assembly of clusters, is currently underway. ${ }^{6}$ As one can imagine, prospective candidates are limited, not only by the obvious paucity of theoretical calculations, but by the lack of experimental evidence for those clusters which readily retain desirable properties. It is therefore understandable why aluminum, being a free electron system, has been so thoroughly studied, ${ }^{7}$ since it is readily amendable to theory and previous experimental results have shown the unique stability that intrinsically exists.

This pronounced stability also provides substantial insight into the role of the frontier orbitals in reactivity. Leuchtner and co-workers, ${ }^{8}$ for example, showed the unique stability of $\mathrm{Al}_{13}^{-}, \mathrm{Al}_{23}^{-}$, and $\mathrm{Al}_{37}^{-}$in the presence of oxygen, while Leskiw and Castleman ${ }^{9}$ revealed similar findings for $\mathrm{AlC}^{-}$and $\mathrm{Al}_{7} \mathrm{C}^{-}$. These observed stable cluster species essentially contain a sufficient number of valence electrons that correspond to the predicted electronic shell closings of the Jellium model ${ }^{10,11}$ and, as a result, confirm its applicability. In the present article, an experimental and theoretical investigation of stable aluminum-nitrogen cluster species is presented, with particular emphasis placed on the applicability of a composite Jellium ${ }^{9}$ system and the prospects of forming cluster assembled materials.

\section{EXPERIMENT}

The apparatus used in this study is a fast flow reactor ${ }^{12,13}$ in which an aluminum rod is vaporized in the presence of a helium carrier gas and a small percentage of nitrogen. The ablated species, upon mixing with these gases, exit a conical nozzle and enter a flow tube. As the thermalized cluster ions proceed toward the detector, additional species (oxygen) may be added, through a reactant gas inlet (RGI), to establish the stability of the cluster distribution. The cluster ions are mass selected with a quadrupole mass analyzer and subsequently detected with a channeltron electron multiplier.

\section{RESULTS}

Figure 1 shows the distribution of pure $\mathrm{Al}_{n}^{-}(n$ $=2-28)$ clusters while Fig. 2 illustrates an obtained $\mathrm{Al}_{n}^{-}(n=2-21), \mathrm{Al}_{n} \mathrm{~N}_{m}^{-}(n=2-20, m=1-3)$ cluster distribution. Although the $m=1$ variety $\left(\mathrm{Al}_{n} \mathrm{~N}^{-}\right)$appear as the most abundant species in the spectra (Fig. 2), $\mathrm{Al}_{n} \mathrm{~N}_{m}^{-}(m$ $=2$ and 3) species are indeed present, but are only readily discernible at low ion intensities, or after oxygen addition. Figure 3 not only demonstrates the progressive decrease in the initial distribution after the addition of $50 \mathrm{sccm}$ (standard cubic centimeters per minute) of oxygen, it hints at the stable entities that emerge as the harsh reactive oxygen environment intensifies. In Fig. 4, $200 \mathrm{sccm}$ of oxygen have been added through the RGI, and the stable species are dominant. The enhanced intensity of particular clusters can be accounted for in terms of the etching of higher order species that feed smaller ones of greater stability.

\section{DISCUSSION}

The basis behind the search for stable cluster species has been rooted in the fundamental differences in the properties of matter for the bulk state and systems of limited size. 


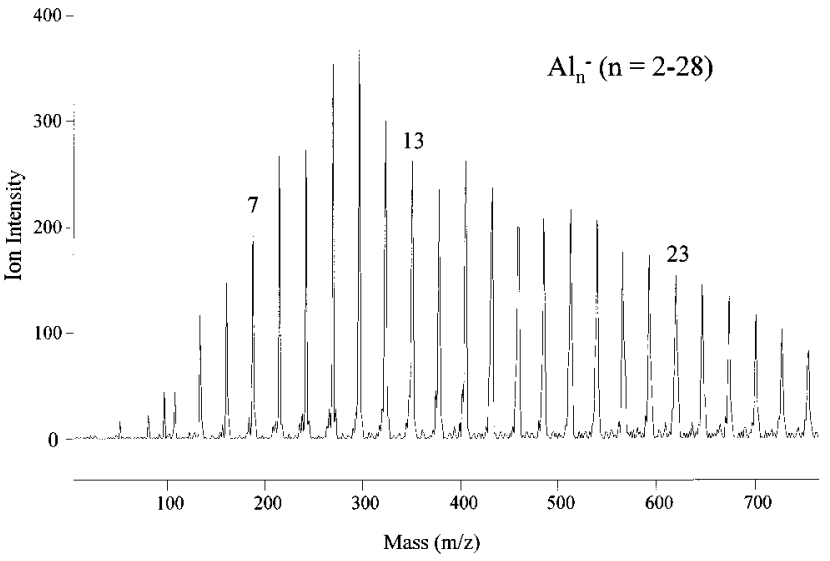

FIG. 1. Pure aluminum anion cluster distribution obtained using a laser vaporization source without reactant gas.

These discrepancies have thus lead to the prospects of forming new materials with unique properties such that all are retained at bulk proportions. Of course, problems stem in identifying suitable candidates, but the use of the Jellium concept, for example, seems to be a valuable starting point for assessing those species that warrant additional consideration.

The observed stability of $\mathrm{Al}_{2} \mathrm{~N}^{-}$in the presence of oxygen is shown in Fig. 4 and can be explained through its behavior as an eight-electron "Jellium-like" species. ${ }^{9}$ In this model, clusters containing $2,8,18,20, \ldots$ valence electrons correspond to the filled electronic shells and are particularly stable. Al is a trivalent metal, and the electronic configuration of an $\mathrm{Al}$ atom is $3 s^{2} 3 p^{1}$ with the spacing between the $3 s$ and $3 p$ states being $4.79 \mathrm{eV}$. As the $\mathrm{Al}$ atoms are brought together, the bond formation leads to an overlap between the bands formed out of $s$ and $p$ states and the metallic character sets in. In the case of pure $\mathrm{Al}_{n}$ clusters, such a transition is proposed to occur around $\mathrm{Al}_{9}$. Below this size, however, the $s$ and $p$ states remain separated and $\mathrm{Al}$ behaves as a monovalent atom. Since $\mathrm{N}$ has five valence electrons, $\mathrm{Al}_{2} \mathrm{~N}^{-}$can be

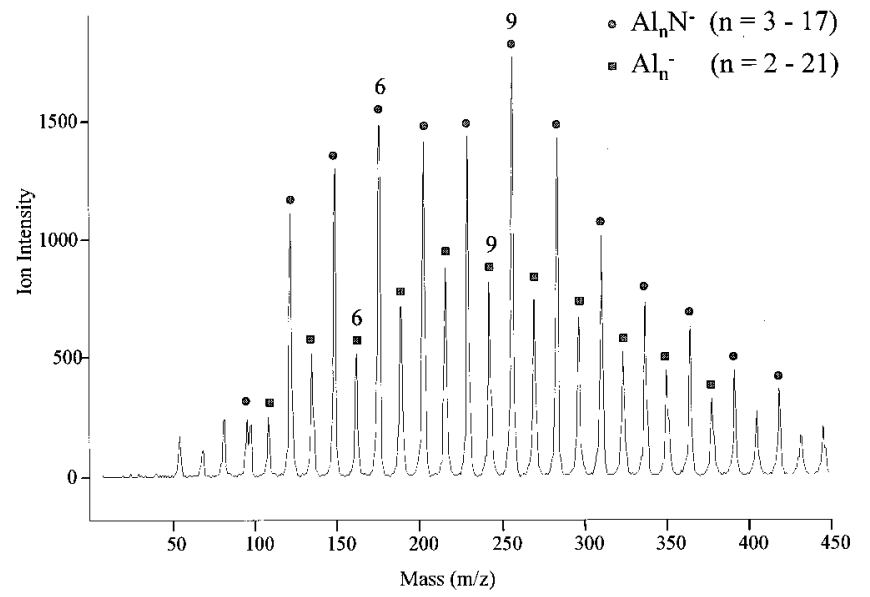

FIG. 2. Distribution of aluminum and aluminum-nitrogen anion clusters obtained by introducing nitrogen gas into the laser vaporization source. Note: $\mathrm{Al}_{n} \mathrm{~N}_{m}^{-}$distribution is typically of greater intensity than the proximate $\mathrm{Al}^{-}$distribution.

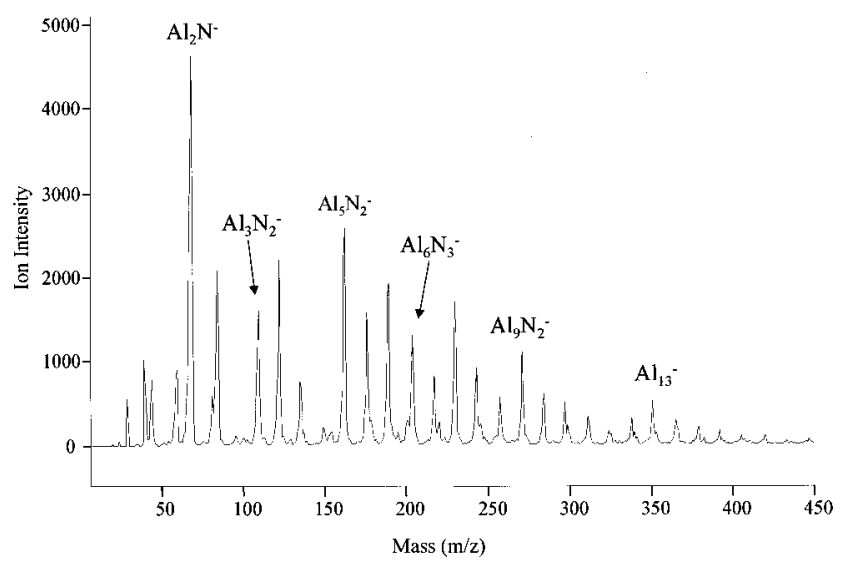

FIG. 3. Distribution of $\mathrm{Al}_{n} \mathrm{~N}_{m}^{-}$with the addition of $50 \mathrm{sccm}$ oxygen.

considered an eight-electron system. The stability of $\mathrm{Al}_{3} \mathrm{~N}_{2}^{-}$, $\mathrm{Al}_{6} \mathrm{~N}_{3}^{-}$, and $\mathrm{Al}_{8} \mathrm{~N}_{3}^{-}$could also be explained in accordance with the Jellium model with the stability of $\mathrm{Al}_{5} \mathrm{~N}_{2}^{-}$and $\mathrm{Al}_{9} \mathrm{~N}_{2}^{-}$demonstrating conformity to the composite Jellium concept.

\section{THEORETICAL CONSIDERATIONS}

Admittedly, the Jellium concept is an oversimplified approach for deducing the properties and accounting for observations of cluster reactivities. It does, however, provide some general guidance towards searching for species that may be useful candidates when considering the nearly infinite variety that are available. Ab initio calculations are therefore needed to understand the experimental findings and to identify potential candidates when forming cluster materials. We have therefore carried out electronic structure calculations on anionic and neutral $\mathrm{Al}_{n} \mathrm{~N}$ clusters containing up to eight $\mathrm{Al}$ atoms.

The theoretical studies were carried out using a linear combination of atomic orbitals molecular orbital approach. ${ }^{14}$ The molecular orbitals were formed out of atomic orbitals located at the atomic sites. The atomic orbitals in turn were expressed as a linear combination of Gaussian functions while the exchange correlation effects were incorporated using a density functional approach. ${ }^{15} \mathrm{~A}$ gradient-corrected

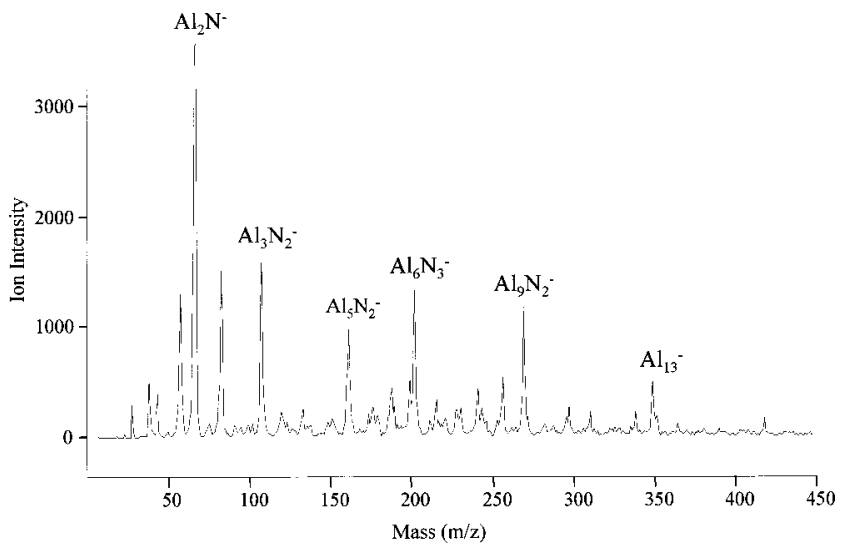

FIG. 4. Distribution of $\mathrm{Al}_{n} \mathrm{~N}_{m}^{-}$with the addition of $200 \mathrm{sccm}$ oxygen. 
TABLE I. Multiplicity, bond lengths, and atomization energies (AE) for $\mathrm{AlN}$ and $\mathrm{AlN}^{-}$dimers.

\begin{tabular}{llcll}
\hline \hline Molecule & \multicolumn{1}{c}{ Source } & Multiplicity & $\begin{array}{c}\text { Bond length } \\
(\AA)\end{array}$ & $\begin{array}{c}\mathrm{AE} \\
(\mathrm{eV})\end{array}$ \\
\hline \multirow{2}{*}{ AlN } & Present & 3 & 1.79 & 3.04 \\
& $\begin{array}{l}\text { Previous } \\
\text { (Refs. 19 and 20) }\end{array}$ & 3 & $1.79,1.80$ & $2.45,2.78$ \\
& Expt. (Ref. 21) & & 1.79 & 3.08 \\
\multirow{2}{*}{$\mathrm{AlN}^{-}$} & Present & 2 & 1.72 & 4.59 \\
& Previous (Ref. 20) & 2 & 1.71 & 3.96 \\
\hline \hline
\end{tabular}

density functional recently proposed by Perdew et al. ${ }^{16}$ was used. All the calculations were done at the all-electron level and the multicenter integrals required to solve the KohnSham equations were calculated by integrating numerically over a mesh of points. The actual calculations were done using the NRLMOL ${ }^{17}$ code developed by Pederson and Jackson. The basis set consisted of $6 s, 5 p$, and $3 d$ Gaussian functions for $\mathrm{Al}$ and $5 s, 4 p$, and $3 d$ Gaussian functions for $\mathrm{N}$. These were supplemented by one $d$ function in each case. These basis functions are well tested ${ }^{18}$ and the reader is referred to earlier papers ${ }^{17}$ for details. In all cases, several initial configurations were used and the geometry was optimized without symmetry constraint by moving the atoms in the direction of forces. The final geometries therefore include possible Jahn-Teller distortions.

One can estimate the accuracy of the calculations by comparing the results of calculations on atoms and dimers for which experiments or the previous calculations exist. For $\mathrm{Al}$ and $\mathrm{N}$ atoms we obtain ionization potentials of 6.07 and $14.73 \mathrm{eV}$, respectively, with the corresponding experimental
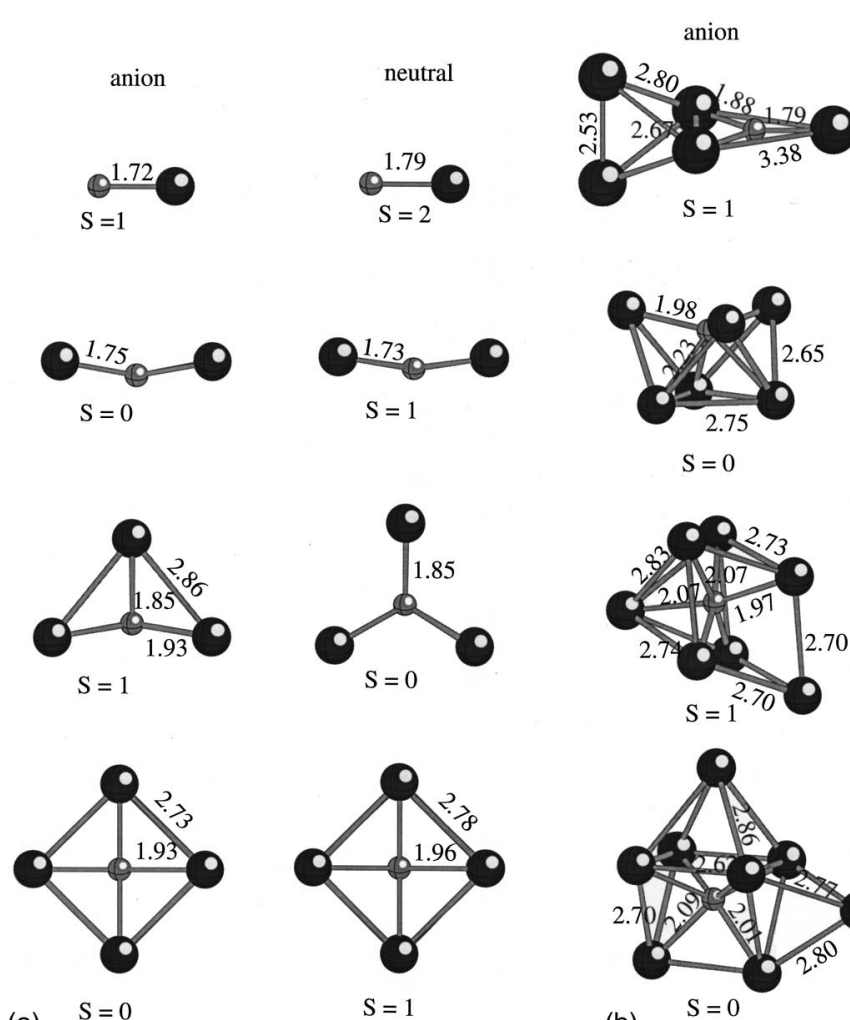

(a)

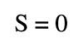

$\mathrm{S}=1$
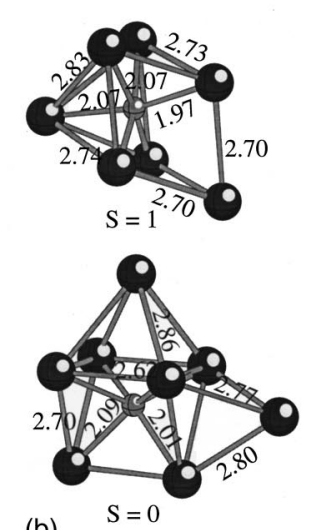

(b) values being 5.99 and $14.53 \mathrm{eV}$. In Table I we have compared the ground state spin multiplicity, bond length, and the atomization energy (AE) of $\mathrm{AlN}$ and $\mathrm{AlN}^{-}$with previous $^{19-21}$ theoretical and experimental studies. Note that our calculated spin multiplicities agree with previous calculations based on the coupled cluster approach. The present $\mathrm{AE}$ are, however, slightly higher but, in the absence of experimental data, it is difficult to judge which result is more accurate.

Figure 5 shows the ground state geometries, bond length, and the spin multiplicities of the anionic and neutral $\mathrm{Al}_{n} \mathrm{~N}$ clusters. The ground state structure for $\mathrm{Al}_{2} \mathrm{~N}$ is bent while the neutral and anionic $\mathrm{Al}_{3} \mathrm{~N}$ clusters have $\mathrm{a}_{3 h}$ and $\mathrm{C}_{2 v}$ structure, respectively; the addition of the electron to the neutral cluster evidently has a large effect on geometry. For $\mathrm{Al}_{4} \mathrm{~N}$, the anion and the neutral both have a $\mathrm{D}_{4 h}$ ground state. The geometry of $\mathrm{Al}_{5} \mathrm{~N}$ could be envisioned as an $\mathrm{Al}_{3} \mathrm{~N}$ cluster with an $\mathrm{Al}_{2}$ dimer attached to one side while $\mathrm{Al}_{6} \mathrm{~N}^{-}$can be considered as a distorted octahedron with a central $\mathrm{N}$ atom. $\mathrm{Al}_{6} \mathrm{~N}$, however, is a distorted $\mathrm{D}_{2 d}$ structure, and in $\mathrm{Al}_{7} \mathrm{~N}$ and $\mathrm{Al}_{8} \mathrm{~N}$, the $\mathrm{N}$ atom becomes centrally located. Note that since we plan to discuss the reactivity of these clusters with oxygen molecules and one of the possible channels involves the formation of $\mathrm{NO}_{2}$, such a channel could be excluded in these clusters. Also note that, except for AIN, the ground states all correspond to the lowest spin multiplicities.

Table II contains the AE of the neutral and anionic clusters. For the anionic clusters, the AE corresponds to the dissociation into $\mathrm{Al}^{-}, \mathrm{N}$, and the remaining neutral $\mathrm{Al}$ atoms. To gain insight on the relative stability of various clusters, we have also listed the energy gain as an $\mathrm{Al}$ atom is added to the preceding size $\left(\Delta E_{n}\right.$ and $\left.\Delta E_{0}\right)$. Note that $\mathrm{Al}_{2} \mathrm{~N}^{-}$has the
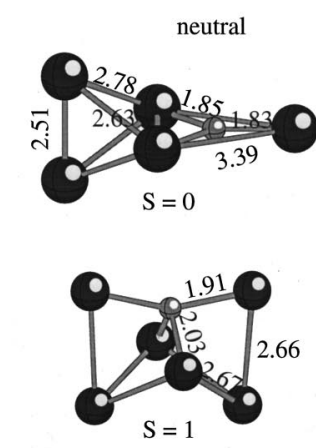

FIG. 5. The ground state geometries and spin multiplicities of neutral and anionic $\mathrm{Al}_{n} \mathrm{~N}^{-} \quad(n=1-8)$ clusters. The small circles are $\mathrm{N}$ atoms while the big circles (not to scale) are Al atoms. Bond lengths are in $\AA$. 
TABLE II. Atomization energy (AE) for the neutral and anionic $\mathrm{Al}_{n} \mathrm{~N}$ ( $n$ $=1-8)$ clusters. $\Delta E_{n}$ and $\Delta E_{0}$ are the differences in energy between clusters with $n$ and $n-1 \mathrm{Al}$ atoms for the anionic and neutral clusters, respectively. The AEA is the adiabatic electron affinity, defined here as the energy difference between the relaxed anion and the relaxed neutral cluster of the same size. $\Delta E_{D}$ is the difference in the atomization energies of the ground state anionic cluster of size $n$ and the neutral cluster of size $n-1$.

\begin{tabular}{|c|c|c|c|c|c|c|}
\hline \multirow[b]{2}{*}{ Cluster } & \multicolumn{2}{|c|}{ Anion } & \multicolumn{2}{|c|}{ Neutral } & \multirow[b]{2}{*}{ AEA $(\mathrm{eV})$} & \multirow[b]{2}{*}{$\Delta E_{D}$} \\
\hline & $\mathrm{AE}(\mathrm{eV})$ & $\Delta E_{n}$ & $\mathrm{AE}(\mathrm{eV})$ & $\Delta E_{0}$ & & \\
\hline AlN & 4.59 & & 3.04 & & 1.96 & \\
\hline $\mathrm{Al}_{2} \mathrm{~N}$ & 10.05 & 5.46 & 8.25 & 5.21 & 2.22 & 7.01 \\
\hline $\mathrm{Al}_{3} \mathrm{~N}$ & 12.58 & 2.53 & 11.94 & 3.69 & 1.06 & 4.33 \\
\hline $\mathrm{Al}_{4} \mathrm{~N}$ & 15.63 & 3.05 & 13.74 & 1.80 & 2.30 & 3.69 \\
\hline $\mathrm{Al}_{5} \mathrm{~N}$ & 17.37 & 1.74 & 15.96 & 2.22 & 1.82 & 3.63 \\
\hline $\mathrm{Al}_{6} \mathrm{~N}$ & 20.39 & 3.02 & 18.75 & 2.79 & 2.05 & 4.43 \\
\hline $\mathrm{Al}_{7} \mathrm{~N}$ & 23.66 & 3.27 & 22.31 & 3.56 & 1.77 & 4.91 \\
\hline $\mathrm{Al}_{8} \mathrm{~N}$ & 25.77 & 2.11 & 24.09 & 1.78 & 2.10 & 3.46 \\
\hline
\end{tabular}

highest gain in energy and can be considered to be the most stable cluster. $\mathrm{Al}_{2} \mathrm{~N}$ also has a high $\Delta E_{0}$ and is the most stable out of the neutral species. On the other hand, $\mathrm{Al}_{5} \mathrm{~N}^{-}$, $\mathrm{Al}_{8} \mathrm{~N}^{-}, \mathrm{Al}_{4} \mathrm{~N}$, and $\mathrm{Al}_{8} \mathrm{~N}$ appear to be the least energetically stable. Table II also lists the adiabatic electron affinity (AEA) which corresponds to the gain in energy as an electron is added to the neutral cluster. Note that all the even Al atom clusters have higher electron affinity than the proximate odd clusters with $\mathrm{Al}_{3} \mathrm{~N}$ being the lowest.

Before we proceed further, we can compare the current findings with previous studies and experiments. Nayak et $a .^{22}$ have performed negative ion photoelectron spectroscopy experiments on $\mathrm{Al}_{3} \mathrm{~N}^{-}$and $\mathrm{Al}_{4} \mathrm{~N}^{-}$clusters and have also carried out density functional calculations. Our calculated ground states for anionic and neutral $\mathrm{Al}_{3} \mathrm{~N}$ and $\mathrm{Al}_{4} \mathrm{~N}$ are similar to their results. For $\mathrm{Al}_{3} \mathrm{~N}$, our calculated AEA of $1.06 \mathrm{eV}$ is comparable to their experimental value of $0.96 \mathrm{eV}$ and their calculated value of $1.0 \mathrm{eV}$. For $\mathrm{Al}_{4} \mathrm{~N}$, our calculated value of $2.30 \mathrm{eV}$ is also comparable to their experimental value of $2.32 \mathrm{eV}$ and their calculated value of $2.29 \mathrm{eV}$. Their experimental photoelectron spectra on $\mathrm{Al}_{3} \mathrm{~N}^{-}$show peaks at 1.19 and $2.62 \mathrm{eV}$. The ground state of $\mathrm{Al}_{3} \mathrm{~N}^{-}$is a doublet and one can consider transitions to singlet and triplet neutral states. For these transitions, their calculations give vertical detachment energies of 1.42 and $2.62 \mathrm{eV}$, respectively, compared to our values of 1.46 and $2.65 \mathrm{eV}$. For $\mathrm{Al}_{4} \mathrm{~N}^{-}$, the experimental spectra show strong features at 2.32 and $3.41 \mathrm{eV}$. Nayak et al. only calculated the vertical transition energy from the anion to the lowest doublet state of the neutral and their calculated value of $2.31 \mathrm{eV}$ is close to the first experimental peak. We calculated vertical transitions from the ground state of the anion to the ground and excited states of the neutral doublet to be 2.32 and $3.19 \mathrm{eV}$, respectively, which are also close to experiment.

We now arrive at the present experiments regarding the reactivity of $\mathrm{Al}_{n} \mathrm{~N}^{-}$clusters and oxygen. The experimental spectra show a strong peak at $\mathrm{Al}_{2} \mathrm{~N}^{-}$. Note that when $\mathrm{Al}_{n} \mathrm{~N}^{-}$ clusters are reacted with $\mathrm{O}_{2}$, a possible reaction channel is the formation of $\mathrm{AlO}_{2}^{-}$, i.e.,

$$
\mathrm{Al}_{n} \mathrm{~N}^{-}+\mathrm{O} 2 \rightarrow \mathrm{Al}_{n-1} \mathrm{~N}+\mathrm{AlO}_{2}^{-} \text {. }
$$

The mass spectra in Figs. 2 and 3 indeed show that the intensity of $\mathrm{AlO}_{2}^{-}$grows after the reaction with oxygen. In a recent paper ${ }^{11}$ it was shown that the total energy gain in forming an $\mathrm{AlO}_{2}^{-}$from an $\mathrm{Al}$ atom, an electron, and $\mathrm{O}_{2}$ is 5.7 $\mathrm{eV}$. Our expectation then would be that those clusters where the total energy required to remove an electron and an $\mathrm{Al}$ atom is less than $5.7 \mathrm{eV}$ would react with $\mathrm{O}_{2}$ to form an $\mathrm{Al}_{n-1} \mathrm{~N}$ species. These clusters would therefore react and diminish in intensity. The last column in Table II lists the energy required to remove an $\mathrm{Al}$ atom and an electron from various clusters. It is gratifying to note that $\mathrm{Al}_{2} \mathrm{~N}^{-}$is the only cluster that is energetically stable against such a reaction. We have also verified that $\mathrm{Al}_{2} \mathrm{~N}^{-}$is stable against a reaction involving the formation of $\mathrm{NO}_{2}$ i.e.,

$$
\mathrm{Al}_{n} \mathrm{~N}^{-}+\mathrm{O}_{2} \rightarrow \mathrm{Al}_{n}^{-}+\mathrm{NO}_{2}
$$

or $\mathrm{NO}_{2}^{-} \cdot \mathrm{Al}_{2} \mathrm{~N}^{-}$is therefore a very stable cluster. An analysis of the electronic structure shows that the gap between the highest occupied molecular orbital (HOMO) and the lowest unoccupied molecular orbital (LUMO) is $2.51 \mathrm{eV}$ and evidently has a closed electronic shell.

We would like to add that the formation of $\mathrm{AlO}_{2}^{-}$is not the only reaction channel. For smaller clusters, the $\mathrm{N}$ atoms can react with $\mathrm{O}_{2}$ to form $\mathrm{NO}_{2}$ or $\mathrm{NO}_{2}^{-}$. For clusters containing more than $5 \mathrm{Al}$ atoms, the $\mathrm{N}$ sites are located on the inside of the cluster in the ground state and it would seem that such a reaction is not possible. However, we have found that these clusters do have energetically close isomers with $\mathrm{N}$ at the outside. For example, Fig. 6 shows the lowest isomer for $\mathrm{Al}_{5} \mathrm{~N}, \mathrm{Al}_{6} \mathrm{~N}$, and $\mathrm{Al}_{7} \mathrm{~N}$ clusters along with their energies relative to the corresponding ground states. Note that for $\mathrm{Al}_{5} \mathrm{~N}$ and $\mathrm{Al}_{6} \mathrm{~N}$, the excited states are only 0.11 and $0.01 \mathrm{eV}$ above the ground state and may exist in the beams. These isomers have exposed $\mathrm{N}$ sites and can react to form $\mathrm{NO}_{2}^{-}$.

As mentioned above, one can try to understand the stability of $\mathrm{Al}_{2} \mathrm{~N}^{-}$and other clusters using a simple Jellium concept. However, due to the spacing between the $3 s$ and $3 p$ states in an $\mathrm{Al}$ atom, $\mathrm{Al}$ behaves as a monovalent atom in small clusters. ${ }^{23} \mathrm{Al}_{2} \mathrm{~N}^{-}$can then be regarded as an eightelectron system. We would, however, like to point out that such a simplistic approach is not absent of problems. The electronic configuration of a $\mathrm{N}$ atom is $2 s^{2} 2 p^{3}$ and the separation between the $s$ and $p$ states in a $\mathrm{N}$ atom is $4.79 \mathrm{eV}$. This $s-p$ separation is larger than in $\mathrm{Al}$ and if one uses the same argument as for the case of $\mathrm{Al}, \mathrm{a} \mathrm{N}$ atom would contribute three and not five valence electrons. Such an assignment would not lead to a filled shell in a Jellium model. Present $a b$ initio studies also do not show any abnormally high electron affinity characteristic of filled Jellium shells. It is then surprising that despite these problems, the model does seem to make correct predictions.

\section{CONCLUSION}

Experiments on aluminum-nitrogen clusters have been carried out to search for highly stable clusters that could serve as the building blocks for cluster assembled materials. The observed mass spectra obtained after reacting the clusters with oxygen show that $\mathrm{Al}_{2} \mathrm{~N}^{-}, \mathrm{Al}_{3} \mathrm{~N}_{2}^{-}, \mathrm{Al}_{5} \mathrm{~N}_{2}^{-}, \mathrm{Al}_{6} \mathrm{~N}_{3}^{-}$, 
a.)

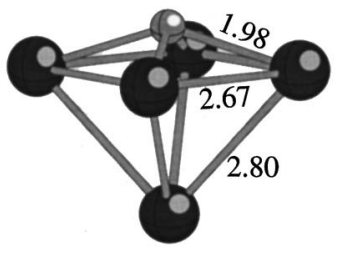

$\mathrm{S}=1$

$\Delta \mathrm{E}=+0.11 \mathrm{eV}$

b.)

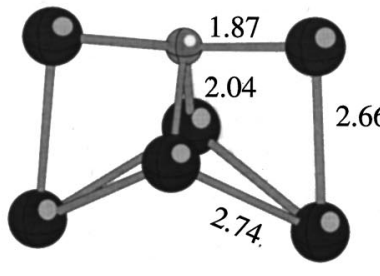

$S=2$

$\Delta \mathrm{E}=+0.01 \mathrm{eV}$

c.)

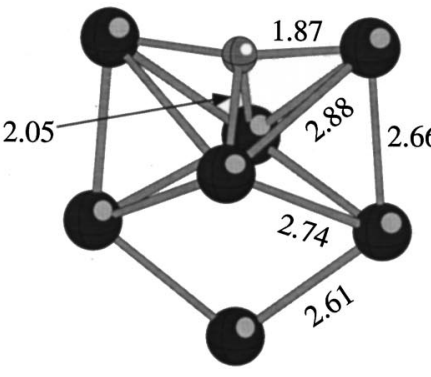

$S=1$

$\Delta \mathrm{E}=+0.43 \mathrm{eV}$

FIG. 6. The geometries and spin multiplicities of low energy anionic $\mathrm{Al}_{n} \mathrm{~N}^{-}$ $(n=5-7)$ clusters. The small circles are $\mathrm{N}$ atoms while the big circles (not to scale) are $\mathrm{Al}$ atoms. Bond lengths are in $\AA$. $\Delta E$ is the energy above the corresponding ground state.

$\mathrm{Al}_{8} \mathrm{~N}_{3}^{-}$, and $\mathrm{Al}_{9} \mathrm{~N}_{2}^{-}$are particularly stable. A simple Jellium model can be used to understand the stability of these clusters. The $a b$ initio calculations on $\mathrm{Al}_{n} \mathrm{~N}$ clusters have been carried out to quantitatively examine the energetics of the reaction and these studies show that the prominent reaction channel is the formation of $\mathrm{AlO}_{2}^{-}$. Those anionic clusters where the energy required to remove an electron and an $\mathrm{Al}$ atom is less that $5.70 \mathrm{eV}$ are stable against such a reactions.
For clusters containing a single $\mathrm{N}$ atom, $\mathrm{Al}_{2} \mathrm{~N}^{-}$is shown to correspond to such a cluster and may be an ideal candidate for the cluster assemblies.

\section{ACKNOWLEDGMENTS}

S.N.K. and C.A. are thankful to the Department of Energy (Grant No. DE-FG02-96ER45579) for financial support. B.D.L. and A.W.C. also gratefully acknowledge financial support from the Department of Energy (Grant No. DEFG02-92ER14258).

${ }^{1}$ A. W. Castleman, Jr. and K. H. Bowen, J. Phys. Chem. 100, 12911 (1996).

${ }^{2}$ Small Particles and Inorganic Clusters, edited by H. H. Anderson (Springer, New York, 1997).

${ }^{3}$ Cluster Assembled Materials, edited by K. Sattler (Trans Tech, 1996).

${ }^{4}$ H. W. Kroto, J. R. Heath, S. C. O'Brien, R. F. Curl, and R. E. Smalley, Nature (London) 318, 162 (1985).

${ }^{5}$ B. C. Guo, K. P. Kerns, and A. W. Castleman, Jr., Science 255, 1411 (1992).

${ }^{6}$ S. N. Khanna and P. Jena, Phys. Rev. Lett. 69, 1664 (1992); Phys. Rev. B 51, 13705 (1995).

${ }^{7}$ B. K. Rao and P. Jena, J. Chem. Phys. 111, 1890 (1999).

${ }^{8}$ R. E. Leuchtner, A. C. Harms, and A. W. Castleman, Jr., J. Chem. Phys. 91, 2753 (1989).

${ }^{9}$ B. D. Leskiw and A. W. Castleman, Jr., Chem. Phys. Lett. 316, 31 (2000).

${ }^{10}$ W. D. Knight, K. Clemenger, W. A. de Heer, W. A. Saunders, M. Y. Chou, and M. L. Cohen, Phys. Rev. Lett. 52, 2141 (1984); S. Saito and S. Ohnishi, ibid. 59, 190 (1980).

${ }^{11}$ C. Ashman, S. N. Khanna, and M. R. Pederson, Chem. Phys. Lett. 324, 137 (2000).

${ }^{12}$ A. W. Castleman, Jr., K. G. Weil, S. W. Sigsworth, R. E. Leuchtner, and R. G. Keesee, J. Chem. Phys. 86, 3829 (1987).

${ }^{13}$ R. E. Leuchtner, A. C. Harms, and A. W. Castleman, Jr., J. Chem. Phys. 92, 6527 (1990)

${ }^{14}$ W. J. Hehre, L. Radom, P. von R. Schleyer, and J. A. Pople, Ab Initio Molecular Orbital Theory (Wiley, New York, 1986).

${ }^{15}$ W. Kohn and L. J. Sham, Phys. Rev. 140, A1133 (1965).

${ }^{16}$ J. P. Perdew, K. Burke, and M. Ernzerhof, Phys. Rev. Lett. 77, 3865 (1996).

${ }^{17}$ M. R. Pederson and K. A. Jackson, Phys. Rev. B 41, 7453 (1990); K. A. Jackson and M. R. Pederson, ibid. 42, 3276 (1990).

${ }^{18}$ D. V. Porezag and M. R. Pederson, Phys. Rev. A 60, 2840 (1999).

${ }^{19}$ G. L. Gutsev, P. Jena, and R. J. Bartlett, J. Chem. Phys. 110, 2928 (1999).

${ }^{20}$ S. K. Nayak, S. N. Khanna, and P. Jena, Phys. Rev. B 57, 3787 (1998).

${ }^{21}$ K. P. Huber and G. Herzberg, Constants of Diatomic Molecules (Nostrand-Reinhold, New York, 1979).

${ }^{22}$ S. K. Nayak, B. K. Rao, and P. Jena, Chem. Phys. Lett. 301, 379 (1999).

${ }^{23}$ X. Li, H. Wu, X. B. Wang, and L. S. Wang, Phys. Rev. Lett. 81, 1909 (1998) 